\title{
Food safety in Thailand 4: Comparison of pesticide residues found in three commonly consumed vegetables purchased from local markets and supermarkets in Thailand
}

\author{
Sompon Wanwimolruk ${ }^{\text {Corresp., }}{ }^{1}$, Kamonrat Phopin ${ }^{1,2}{ }^{2}$, Somchai Boonpangrak ${ }^{1}$, Virapong Prachayasittikul \\ ${ }^{1}$ Center for Research and Innovation, Faculty of Medical Technology, Mahidol University, Bangkok 10700, Thailand \\ 2 Department of Clinical Microbiology and Applied Technology, Faculty of Medical Technology, Mahidol University, Bangkok 10700, Thailand \\ Corresponding Author: Sompon Wanwimolruk \\ Email address: sompon-999@hotmail.com
}

Background The wide use of pesticides raises concerns on the health risks associated with pesticide exposure. For developing countries, like Thailand, pesticide monitoring program (in vegetables and fruits) and also the maximum residue limits (MRL) regulation have not been entirely implemented. The MRL is a product limit, not a safety limit. The $M R L$ is the maximum concentration of a pesticide residue (expressed as $\mathrm{mg} / \mathrm{kg}$ )

recommended by the Codex Alimentarius Commission to be legally permitted in or on food commodities and animal feeds (Codex Alimentarius Commission, 2015; European Commission, 2008; European Commission, 2015). MRLs are based on supervised residue trial data where the pesticide has been applied in accordance with GAP (Good Agricultural Practice). This study aims at providing comparison data on pesticide residues found in three commonly consumed vegetables (Chinese kale, pakchoi and morning glory) purchased from some local markets and supermarkets in Thailand. Methods These vegetables were randomly bought from local markets and supermarkets. Then they were analyzed for the content of 28 pesticides by using GC-MS/MS. Results Types of pesticides detected in the samples either from local markets or supermarkets were similar. The incidence of detected pesticides was 100\% (local markets) and 99\% (supermarkets) for the Chinese kale; 98\% (local markets) and 100\% (supermarkets) for the pakchoi; and 99\% (local markets) and 97\% (supermarkets) for the morning glory samples. The pesticides were detected exceeding their MRL at a rate of $48 \%$ (local markets) and 35\% (supermarkets) for the Chinese kale; 71\% (local markets) and 55\% (supermarkets) for the pakchoi, and $42 \%$ (local markets) and $49 \%$ (supermarkets) for the morning glory.

Discussion These rates are much higher than those seen in developed countries. It should be noted that these findings were assessed on basis of using criteria (such as MRL) obtained from developed countries. Our findings were also confined to these vegetables sold in a few central provinces of Thailand and did not reflect for the whole country as 
sample sizes were small. Risk assessment due to consuming these pesticide contaminated vegetables, still remains to be evaluated. However, remarkably high incidence rates of detected pesticides give warning to the Thai authorities to implement proper regulations on pesticide monitoring program. Similar incidence of pesticide contamination found in the vegetables bought from local markets and supermarkets raises question regarding the quality of organic vegetables domestically sold in Thailand. This conclusion excludes Thai export quality vegetables and fruits routinely monitored for pesticide contamination before exporting. 
2

3

\section{Original Article}

\section{Food safety in Thailand 4: Comparison of pesticide residues found in three commonly consumed vegetables purchased from local markets and supermarkets in Thailand}

\section{Sompon Wanwimolruk ${ }^{1 *}$, Kamonrat Phopin ${ }^{1,2}$, Somchai Boonpangrak ${ }^{1}$ and Virapong Prachayasittikul ${ }^{2}$}

${ }^{1}$ Center for Research and Innovation, Faculty of Medical Technology, Mahidol University, Bangkok 10700, Thailand

${ }^{2}$ Department of Clinical Microbiology and Applied Technology, Faculty of Medical Technology, Mahidol University, Bangkok 10700, Thailand

*Corresponding author: Sompon Wanwimolruk, Ph.D.

Professor, Faculty of Medical Technology, Mahidol University, Bangkok 10700, Thailand E-mail: sompon.wan@mahidol.ac.th; sompon-999@hotmail.com, Phone +66 24414370 ; Fax: +6624414380

Running Title: Pesticide residues found in vegetables bought from local and supermarkets 


\section{ABSTRACT}

Background The wide use of pesticides raises concerns on the health risks associated with

pesticide exposure. For developing countries, like Thailand, pesticide monitoring program (in vegetables and fruits) and also the maximum residue limits (MRL) regulation have not been entirely implemented. The MRL is a product limit, not a safety limit. The MRL is the maximum concentration of a pesticide residue (expressed as $\mathrm{mg} / \mathrm{kg}$ ) recommended by the Codex Alimentarius Commission to be legally permitted in or on food commodities and animal feeds (Codex Alimentarius Commission, 2015; European Commission, 2008; European Commission, 2015). MRLs are based on supervised residue trial data where the pesticide has been applied in accordance with GAP (Good Agricultural Practice). This study aims at providing comparison data on pesticide residues found in three commonly consumed vegetables (Chinese kale, pakchoi and morning glory) purchased from some local markets and supermarkets in Thailand. Methods These vegetables were randomly bought from local markets and supermarkets. Then they were analyzed for the content of 28 pesticides by using GC-MS/MS. Results Types of pesticides detected in the samples either from local markets or supermarkets were similar. The incidence of detected pesticides was 100\% (local markets) and 99\% (supermarkets) for the Chinese kale; $98 \%$ (local markets) and 100\% (supermarkets) for the pakchoi; and 99\% (local markets) and 97\% (supermarkets) for the morning glory samples. The pesticides were detected exceeding their MRL at a rate of $48 \%$ (local markets) and 35\% (supermarkets) for the Chinese kale; $71 \%$ (local markets) and 55\% (supermarkets) for the pakchoi, and 42\% (local markets) and 49\% (supermarkets) for the morning glory. Discussion These rates are much higher than those seen in developed countries. It should be noted that these findings were assessed on basis of using criteria (such as MRL) obtained from developed countries. Our findings were also confined to these vegetables sold in a few central provinces of Thailand and did not reflect for the whole country as sample sizes were small. Risk assessment due to consuming these pesticide contaminated vegetables, still remains to be evaluated. However, remarkably high incidence rates of detected pesticides give warning to the Thai authorities to implement proper regulations on pesticide monitoring program. Similar incidence of pesticide contamination found in the vegetables bought from local markets and supermarkets raises question regarding the quality of 
64 quality vegetables and fruits routinely monitored for pesticide contamination before

65

66

67

68

69

70

71

72

73

74

75

76

77

78

79

80

81

82

83

84

85

86

87

88

89

90

91

92

93

94

\section{exporting.}

Keywords: Pesticide residues, Vegetables, Chinese kale, Pakchoi, Morning glory, Food safety

\section{INTRODUCTION}

An enormous concern on toxic pesticides in foods has been raised because of its negative health and environmental impacts. This is due to the widespread use of pesticides in agriculture. In fact, the main exposure to pesticides for humans is oral ingestion, especially by vegetables and fruits (Claeys et al., 2008; Drouillet-Pinard et al., 2011). Toxicity and human health risk associated with pesticide contamination in foods has made it necessary to regulate pesticide residues in our foods (Cervera et al., 2014). Detection and quantification of pesticide residues in food samples are essential to verify whether these pesticides are within limits, so called "maximum residue limits (MRL)". This regulation was established by the European Commission and other regulatory authorities. Many developed countries have approved this regulation to oversee and operate their food safety affair. Contrastingly, in developing countries such as Thailand, good agricultural practices (GAP) have not fully been implemented, nor has a successful pesticide monitoring program. Exception is for those produce that will be exported. Pesticides have been greatly used in agriculture in Thailand (Harnpicharnchai et al., 2013). The most popular classes of pesticides imported into Thailand are herbicides, followed by insecticides and fungicides (Sapbamrer \& Nata, 2014). Among the insecticides, organophosphates and carbamates are very commonly used for protecting crops from insects' invasion. The use of pesticides in agriculture has been linked with occupational health of farmers, gardeners and consumers (Chan, 1990; Sapbamrer \& Nata, 2014).

Chinese kale (Brassica oleracea) is also known as Chinese broccoli. Chinese kale is a leaf vegetable appearing thick and flat, with glossy blue-green leaves, thick stems and a small number of tiny, almost vestigial flower heads similar to those of broccoli. Flavour of Chinese kale is very like to that of broccoli, but somewhat bitterer. Chinese kale is used extensively in Chinese cuisine, and especially in Cantonese cuisine. In Thailand, a number of admired Thai dishes have Chinese kale as a principal ingredient. In some dishes, Chinese kale is consumed 
95 fresh, without cooking. This possesses potential for toxicity if the vegetables are eaten freshly 96 every day without washing them properly. Pakchoi [Brassica chinensis Jusl var parachinensis 97 (Bailey) Tsen \& Lee] is a species in the Brassicaceae which is a popular vegetable consumed in 98 Thailand, also in Southeast Asia and southern China. Unlike napa cabbage (Brassica pekinensis), 99 pakchoi does not form heads; instead, they have smooth, dark green leaf blades forming a cluster reminiscent of mustard or celery. Water morning glory (Ipomoea aquatic Forsk) is a semiaquatic, tropical plant grown as a vegetable in East, South and Southeast Asia. It is also known as water spinach, water convolvulus, or by the more ambiguous names Chinese spinach, Chinese convolvulus or swamp cabbage (Nagendra Prasad et al., 2008). It is known as pak bung in Thai, ong choy in Chinese and kangkong in Tagalog. Water morning glory is one of the most popular vegetables constituted in Thai, Burmese, Lao, Cambodian, Malay, Vietnamese, Filipino, and Chinese cuisines.

Pesticide residues have been found in many raw agricultural commodities such as vegetables and fruits, and processed foods worldwide in the past decades (Chen et al., 2011; Chen et al., 2014; Huan et al., 2015; Li et al., 2014; Osei-Fosu et al., 2014; Sapbamrer \& Hongsibsong, 2014; Wang et al., 2013; Wanwimolruk et al., 2015a; Wanwimolruk et al., 2015b). Presently, information on pesticide contamination in vegetables in Thailand is limited and systemic investigation is desired to verify the current status of pesticide contamination in foods,

113 particularly in vegetables and fruits. Also, the current case of organic fruits and vegetables sold

114 in Thailand displays to consumers with no confidence in regard to quality whether the produce is 115 pesticide-free. Many supermarkets have placed labels on fruits and vegetables implying that they 116 are either organically grown or pesticide-free. The supermarkets in Thailand sell not only organic 117 produce. The fresh vegetables sold in supermarkets in Thailand can be categorized into four 118 groups, i.e., conventional, organic, pesticide-free and safe vegetables. Regarding the latter 119 category, the Thai people have questioned if they are pesticide-free or organic vegetables. 120 Consequently, people are prepared to buy vegetables and fruits from supermarkets at much 121 higher price than those from local markets. This is because they have a high expectation that 122 supermarket produce is safe from pesticide contamination. However, there is no scientific-based 123 evidence to verify the supermarkets' claims and people's beliefs. Therefore, the purpose of this 124 study was to provide comparison data on pesticide residues found in three commonly consumed 125 vegetables (Chinese kale, pakchoi and water morning glory) purchased from local markets and 
126 supermarkets. In addition, this study had no intention to compare the conventionally grown and 127 organically grown vegetables. However, the present study raises questions about the quality of 128 organically grown vegetables in Thailand.

\section{MATERIALS AND METHODS}

\section{Chemicals and standards}

Anhydrous magnesium sulphate, sodium chloride, primary and secondary amine (PSA, 134 particle size $40 \mu \mathrm{m}$ ), graphite carbon black (GCB) and C18 sorbent (particle size $40 \mu \mathrm{m}$ ) were 135 obtained from Supelco (Sigma-Aldrich Corp., St. Louis, USA). HPLC-grade acetonitrile was 136 purchased from Merck (Darmstadt, Germany). Twenty eight pesticides and two metablolite 137 standards including aldrin, atrazine, captan, carbaryl, carbofuran (and its two metabolites 138 carbofuran-3-hydroxy and carbofuran-3-keto), carbosulfan, chlormefos, chlorpyrifos, 139 chlorothalonil, $\lambda$-cyhalothrin, cypermethrin, deltamethrin, diazinon, dichlorvos, dicofol, 140 dimethoate, ethion, fenitrothion, fenvalerate, malathion, metalaxyl, methidathion, methomyl, 141 paraoxon-methyl, phosalone, pirimicarb, pirimiphos-methyl and profenofos were purchased from 142 Dr. Ehrenstorfer (Augsburg, Germany). Purity of these pesticide standards was $>98 \%$. Individual 143 stock of standard solutions $(1000 \mathrm{mg} / \mathrm{L})$ was prepared in acetonitrile.

\section{Vegetable samples}

146 Three vegetables were selected for this study namely Chinese kale, pakchoi and water morning glory. The selection was based on their high consumption in Thailand. These three vegetables are widely consumed among Thai and Asian people. Chinese kale samples $(\mathrm{n}=137)$ were purchased randomly from local open-air markets $(n=69)$ and supermarkets $(n=68)$. For pakchoi, a total of 125 samples were bought from local markets $(\mathrm{n}=63)$ and supermarkets $(\mathrm{n}=$ 62). Samples of water morning glory $(n=135)$ were purchased randomly from local markets $(n$ $152=74)$ and supermarkets $(n=61)$. These markets were located in central provinces of Thailand 153 including Bangkok, Nakhon Pathom, Nonthaburi, Ayutthaya, Pathumthani, Samutsakorn and 154 Nakhon Ratchasima. These provinces are located surrounding Bangkok, Thailand, within a radial 155 distance of $260 \mathrm{~km}$. The supermarkets which the vegetable samples were bought from were Big 156 C, Foodland, Jiffy Plus, Lemon Farm, Max Valu, Tesco Lotus, Tops and Villa Market. The study 
157 was carried out over a year period from November 2013 to December 2014. At the local markets

158 at which vegetable samples were bought, the produce that was for sale came from conventional

159 farms and was not claimed to be 'organic produce'. The reason we purchased conventional from

160 the local markets was because almost all produce sold in the local markets are known to be

161 conventionally grown. There are only a few produce sold in the local markets that are labelled as

162 organic, whereas the vegetable samples purchased from supermarkets were sorted into four

163 groups, i.e., conventional, organic, pesticide-free and safe vegetables. Most of vegetable samples

164 bought from the supermarkets were claimed to be organic and pesticide-free vegetables. Like for

165 our previous study (Wanwimolruk et al., 2015b), it is very difficult to get the information on the

166 suppliers as most of the workers in both supermarkets and local markets had no idea where the

167 vegetables were bought from. Therefore, we could not obtain accurate information on suppliers.

168 Approximately $500 \mathrm{~g}$ of vegetables were purchased and the samples were transported to the

169 laboratory for analysis which was done within $24 \mathrm{hr}$. The representative portion (150-200 g) of

170 the vegetable sample was chopped into tiny pieces and homogenized using a food processor and

171 mixed carefully. The homogenized samples were then extracted and treated as described in

172 following section.

173

\section{Sample preparation}

175 The analysis of pesticide residues was performed using the pesticide multiresidue

176 QuEChERS (Quick Easy Cheap Effective Rugged and Safe) method as explained previously

177 (Anastassiades et al., 2003; Lehotay, 2007; Lehotay et al., 2010; Paya et al., 2007). Briefly,

178 extraction of pesticides was performed by extracting $15 \mathrm{~g}$ of homogenized vegetable with $15 \mathrm{ml}$

179 acetonitrile saturated with $6 \mathrm{~g}$ of magnesium sulphate and $1.5 \mathrm{~g}$ of sodium chloride. This

180 extraction process was pursued by a cleaning up procedure. This was achieved by transferring

181 the supernatant $(1 \mathrm{~mL})$ into another tube comprising $50 \mathrm{mg}$ of primary-secondary amine (PSA),

$1827.5 \mathrm{mg}$ graphite carbon black (GCB) and $150 \mathrm{mg}$ magnesium sulphate. After shaking and

183 centrifugation, the extract supernatant was then transferred to an autosampler vial for direct

184 injection into the Bruker GC/MS/MS system.

185

186 GC-MS/MS analysis 
187 Detection of pesticides was accomplished by using a Bruker 456 gas chromatography (GC) 188 coupled with Bruker Scion Triple Quadrupole mass spectrometer (GC-MS/MS). Details of GC189 MS/MS conditions were referred to as in the previous reports (Duff and Voglino, 2012;

190 Wanwimolruk et al., 2015b). Multiple reaction monitoring (MRM) acquisition method and two 191 ion transition at the experimentally optimized collision energy (CE) were monitored for each 192 pesticide analyte.

193

\section{Calibration and quantification}

195 A working surrogate spiking standard solutions of pesticides were made by an appropriate 196 dilution of the stock solutions with acetonitrile. These standard solutions were guarded from light 197 and kept frozen at $-20^{\circ} \mathrm{C}$ until required. Calibration curves of each pesticide of interest were conducted using an internal standard method according to the established procedure (Koesukwiwat et al., 2011; Lehotay, 2007; Lehotay et al., 2010; Wanwimolruk et al., 2015b). These were conducted using the same procedure each time when a new unknown sample set was analyzed. Aldrin was used as an internal standard. The ratio of the peak area of the pesticide standard to that of the internal standard was employed for quantification. Recovery studies for method validation were conducted as previously described (Koesukwiwat et al., 2011; Wanwimolruk et al., 2015b). The method validation in regard to reproducibility, calibration linear range, limit of detection (LOD), limit of quantification (LOQ) was performed for each vegetable matrix as expressed previously (Dong et al., 2012; Koesukwiwat et al., 2011). Quantitation of pesticides in an unknown vegetable sample was carried out in duplicate unless otherwise stated. MRL values for each pesticide in the vegetable of interest were quoted from recommended MRL values established by Thailand Ministry of Agriculture and Cooperation (2013), Codex Alimentarius Commission (2015), and European Commission (2015). These three references were used because not all pesticides' MRLs were listed in the individual reference.

\section{Data treatment}

214 Vegetable samples were grouped into two categories, according to the sources where the 215 samples were purchased, i.e., local markets and supermarkets. Pesticide concentrations obtained

216 from the GC-MS/MS analysis were treated separately for each vegetable studied. These data

217 were further evaluated to determine $\%$ total detection of pesticide residues, $\%$ of samples which 
218 pesticides were not detected, \% of samples contained pesticide residues of $<$ MRL, and $\%$ of

219 samples contained pesticide residues of $>$ MRL. For each vegetable of interest the number of

220 samples (or frequency) containing individual pesticide was counted with aid of using Excel

221 Microsoft program. Also the bar graphs were plotted (Excel Microsoft program) from these data

222 to show frequency distribution or bar graphs illustrating types of pesticides in Chinese kale,

223 pakchoi and morning glory, separately. Numbers of samples containing pesticide residues of $>$

224 MRL were determined by using the MRL reference values for each pesticide and for particular

225 commodity. These were also performed by using Excel Microsoft program.

226

227

\section{Statistical analysis}

228

All results are presented as either mean \pm standard deviation (S.D.) or median. The

differences of parameter between two sample groups were assessed by either unpaired Student's $t$-test or the Mann-Whitney $U$-test, depending on their normality of distribution. The statistical significance level was customary to $P<0.05$. All statistical analyses were assessed using the software SPSS statistical package for Windows version 18.0 (SPSS Inc., Chicago, IL, USA).

\section{RESULTS}

235

The GC-MS/MS method was validated to determine efficiency and accuracy of the analytical assay. Excellent linearity of calibration curves of each pesticide standards were attained as illustrated by the coefficient of determination $\left(\mathrm{r}^{2}\right)$ values of $>0.92$. For instance, for Chinese kale, the linearity of calibration curves of all twelve pesticides detected (e.g., cypermethrin, deltamethrin, diazinon, dimethoate, metalaxyl, and profenofos) were excellent with $\mathrm{r}^{2}>0.93$. When the pesticides of interest were assayed at $0.01 \mathrm{ppb}$ the signal-to-noise ratio was well above 30 for all pesticides studied. Therefore, detection limits were below $0.01 \mathrm{ppb}$ using the sample preparation procedures described previously. The precision of the method was verified by the reproducibility of the retention time and peak area. It was noticed that the retention time and peak area of all pesticides were in good precision. The relative standard deviations (RSD) of repeatability for cypermethrin and metalaxyl in Chinese kale samples were $5.2 \%$ and $4.6 \%$, respectively. While the RSD of reproducibility for cypermethrin and metalaxyl in Chinese kale samples were $12.3 \%$ and $9.1 \%$. Overall, their relative RSD of repeatability were lower than $8 \%$ 
249 whereas the RSD of reproducibility were lower than $17 \%$. In general, the mean recoveries of all 250 pesticides studied from fortified samples in five replicated experiments were in the range of 75 $251114 \%$. For example, the mean recovery of carbaryl and metalaxyl in Chinese kale were $102 \pm$ $25211 \%$ and $97 \pm 7 \%$ at a concentration of $100 \mathrm{ppb}$. These ranges of recovery fall within the typical 253 acceptance criteria for quantitative regulatory methods (Koesukwiwat et al., 2011). Similar 254 observations of assay validations were found with respect to other two vegetables studied, i.e. 255 pakchoi and morning glory.

256 Twentyeight pesticides studied were selected on the basis of their widespread use in 257 agriculture in Thailand. Although the most popular classes of pesticides imported into Thailand 258 are herbicides (Sapbamrer \& Nata, 2014), only one herbicide namely atrazine was studied. This 259 was simply due to lack of budget to purchase other pesticide standards. Glyphosate is very 260 commonly used herbicide in Thailand but the analytical assay for glyphosate is rather expensive and not yet available in our laboratory. The GC-MS/MS method employed in this study offered satisfactorily separation with high sensitivity and selectivity for quantitation of all 28 pesticides of interest (Wanwimolruk et al., 2015b). The absence of co-extracted interferences for all varieties of leaf vegetables, Chinese kales, pakchoi and water morning glory, was demonstrated by blank extract analysis showing there was no interfering peak co-eluted with analytes of interest. Moreover, in all vegetable samples tested, there were no identifiable peaks detected with the same retention time as aldrin (retention time $=16.02 \mathrm{~min}$ ) that was used as an internal standard in our GC-MS/MS assay. This supports the rationality of employing aldrin as the internal standard for the assays.

Of 28 pesticides tested, 12 pesticides were detected in the Chinese kale samples purchased from supermarkets (Figure 1). These included carbaryl, carbofuran, chlorothalonil, chlorpyrifos, $\lambda$-cyhalothrin, cypermethrin, deltamethrin, diazinon, dimethoate, malathion, metalaxyl and profenofos. Nevertheless, chlorothalonil and deltamethrin were not detected in those Chinese kale samples purchased from local markets (Figure 1), while malathion was not found in the samples bought from supermarkets. Most of Chinese kale samples ( $88 \%$ in local markets, $91 \%$ in supermarket samples) had multiple pesticide residues. Overall, metalaxyl, dimethoate and diazinon appeared to be the most often found pesticides in the Chinese kale samples from both sources (Figure 1). The occurrence rate of metalaxyl in the local market samples was $91 \%$ (63/69) and was 94\% (64/68) for the supermarket samples. However, none of the Chinese kale 
280 samples purchased from both local markets and supermarkets had metalaxyl that exceeded the 281 recommended MRL value (2000 ppb). Rates of occurrence for dimethoate in the Chinese kale 282 samples were 80\% (55/69) and 88\% (60/68) for the Chinese kale samples from local markets and 283 supermarkets, respectively. Of 69 samples from local markets, 23 of them had dimethoate 284 exceeding the MRL value (20 ppb). This corresponds to a rate greater than dimethoate's MRL of $28533 \%$. Eleven samples purchased from the supermarkets were found to contain dimethoate that 286 exceeded the MRL. These samples exceeded dimethoate's MRL by $16 \%$.

Diazinon was other commonly pesticide detected in the Chinese kale samples studied. It was 288 detected in $62 \%(43 / 69)$ and $74 \%(50 / 68)$ of the Chinese kale samples from local markets and supermarkets, respectively (Figure 1). None of both the local market and supermarket samples had diazinon levels that exceeded the recommended MRL (50 ppb). Three other pesticides were also detected in the Chinese kale samples which were profenofos, cypermethrin and carbaryl.

292 Profenofos was detected in the Chinese kale samples from both sources, with moderate

293

294

295

296

297

298

299

300

301

302

303

304

305

306

307

308 309 occurrence rates of $33 \%$ (23/69) for the local market samples and $29 \%(20 / 68)$ for the supermarket samples. Eleven of the samples purchased from the local markets had profenofos levels exceeding the MRL (10 ppb), whereas twelve samples from the supermarkets contained profenofos at concentrations greater than the recommended MRL. Of note, profenofos concentrations detected in the Chinese kale samples was found to vary widely among the samples from both sources with a range from $0.1-2,095 \mathrm{ppb}$. Pyrethroid pesticide cypermethrin was also detected in the Chinese kale samples at a relatively low rate of detection. Cypermethrin was found in $16 \%(11 / 69)$ of the samples bought from the local market, similarly $15 \%(10 / 68)$ of the supermarket samples contained cypermethrin (Figure 1). One of the local market samples had cypermethrin that exceeded the MRL, while all of the supermarket samples (3 samples) were found to have cypermethrin that exceeded the MRL value (1000 ppb). Carbaryl was detected in $19 \%(13 / 69)$ and 15\% (10/68) of the Chinese kale samples from local markets and supermarkets, respectively (Figure 1). Levels of carbaryl found in these samples ranged from 0.1 to $606 \mathrm{ppb}$, in which two of the supermarket samples contained carbaryl exceeding its MRL value (50 ppb). The rest of pesticides found in the Chinese kale samples were detected with relative low rate of occurrence. These include carbofuran, chlorothalonil, chlorpyrifos, deltamethrin, $\lambda$-cyhalothrin and malathion. 
310 The incidence of pesticide detection, i.e., the \% of total pesticide detection in the Chinese

311 kale samples from both sources were extremely high, that is $100 \%$ and $99 \%$ for the samples

312 bought from the local markets and the supermarkets, respectively. Of interest, the incidence of

313 pesticides detected exceeding the recommended MRL values was $48 \%$ in the Chinese kale

314 samples purchased from the local markets. This was slightly higher than the incidence of

315 pesticide detected exceeding the MRL of 35\% observed in the samples from the supermarkets.

316 Very small samples were found to contain no pesticides; this represents a rate of free of

317 pesticides of $1 \%$ in the supermarket samples.

318 Nine pesticides were detected in both the pakchoi samples purchased from the local markets

319 and the supermarkets (Figure 2). These were carbaryl, carbofuran, chlorpyrifos, $\lambda$-cyhalothrin,

320 cypermethrin, diazinon, dimethoate, metalaxyl and profenofos. Similar to findings observed in

321 the Chinese kale, three pesticides namely metalaxyl, dimethoate and diazinon, were the most

322 often detected in the pakchoi samples collected from both sources. Few pakchoi samples had

323 only one pesticide whereas others (92\% in local markets, 97\% in supermarket samples) had

324 multiple pesticide residues. Profiles of pesticide types detected in the pakchoi samples from both

325 sources were similar. Like the Chinese kale, occurrence of metalaxyl in pakchoi samples was

326 very high at $97 \%(61 / 63)$ for the samples purchased from the local markets, and 98\% (61/62) of

327 the samples from the supermarkets were found to have metalaxyl residues (Figure 2). Among

328 these local market samples, 13 samples (21\%) had metalaxyl levels that exceeded the

329 recommended MRL (50 ppb). For the samples bought from the supermarkets, 11 samples (18\%)

330 had metalaxyl that exceeded the MRL. Dimethoate was found in 94\% (59/63) and 87\% (54/62)

331 of the pakchoi samples from local markets and supermarkets, respectively (Figure 2). Thirty-four

332 samples from the local markets (54\%) had dimethoate levels of greater than the recommended

333 MRL (20 ppb), whereas 23 supermarket samples (37\%) had dimethoate that exceeded its

334 recommended MRL. Rates of occurrence for diazinon in the pakchoi samples were 57\% (36/63)

335 and 65\% (40/62) for the samples from local markets and supermarkets, respectively (Figure 2).

336 None of the pakchoi samples bought from both the local markets and the supermarkets had

337 diazinon levels above the MRL (50 ppb). Carbofuran, chlorpyrifos and cypermethrin were

338 detected in pakchoi samples from both the local market and supermarkets but with moderate

339 occurrence rates. Cypermethrin was found in 19\% (12/63) of the pakchoi samples bought from

340 the local market samples, while $21 \%$ (13/62) of the supermarket samples contained cypermethrin 
341 (Figure 2). Two of the pakchoi samples bought from the local markets were found to have

342 cypermethrin exceeding the recommended MRL (1000 ppb). Five of the pakchoi samples bought

343 from supermarkets had cypermethrin exceeding the MRL. Chlorpyrifos was detected in 11\%

$344(7 / 63)$ of the pakchoi samples purchased from the local markets, whereas $16 \%(10 / 62)$ of the

345 supermarket samples were found to contain chlorpyrifos residues (Figure 2). Two of the pakchoi

346 samples purchased from the local markets and one supermarket sample had chlorpyrifos that

347 exceeded the recommended MRL (1000 ppb). For carbofuran, the pesticide detection rate was

$34832 \%(20 / 63)$ in the local market samples, and 29\% (18/62) in the supermarket samples. Even

349 though other three pesticides including carbaryl, $\lambda$-cyhalothrin and profenofos were also detected

350 in the pakchoi samples but the occurrence rates were relatively low (Figure 2).

351 The total incidence of pesticide detection in the pakchoi samples was $98 \%$ and $100 \%$ for the

352 samples bought from the local markets and from the supermarkets, respectively. The incidence

353 of pesticides detected exceeding the recommended MRL values was $71 \%$ in the pakchoi samples

354 purchased from the local markets. While the incidence of MRL exceedance was 55\% in the

355 pakchoi samples bought from the supermarkets. These left the proportions of pakchoi samples

356 having pesticide residues of less than MRL and without pesticides to be approximately $30 \%$.

357 Of 28 pesticides investigated, 12 different individual pesticides were detected in the water

358 morning glory samples purchased from both the local markets and the supermarkets (Figure 3).

359 Eight common pesticides detected in both the morning glory samples from the local markets and

360 the supermarkets were carbofuran, chlorpyrifos, $\lambda$-cyhalothrin, cypermethrin, diazinon,

361 dimethoate, metalaxyl and profenofos. Few samples contained only one pesticide, but most of

362 them (90\% in local markets, $89 \%$ in supermarket samples) had multiple pesticide residues.

363 Again, similar to Chinese kale and pakchoi, metalaxyl, dimethoate and diazinon appeared to be

364 the most often found pesticides in the water morning glory samples from both sources.

365 Occurrence rates of metalaxyl in morning glory samples were 96\% (71/74) and 93\% (57/61) for

366 the local market and the supermarket samples, respectively. All of the morning glory samples

367 tested had metalaxyl levels below the recommended MRL (2000 ppb). Occurrence rates for

368 dimethoate in the water morning glory samples were $92 \%(68 / 74)$ for the local market samples,

369 and $84 \%$ (51/61) for the samples from supermarkets. Of 74 samples from local markets, 28 of

370 them had dimethoate exceeding the MRL value (20 ppb). This represents a rate of greater than

371 dimethoate's MRL of 38\%. Twenty-two samples purchased from supermarkets were found to 
372 contain dimethoate that exceeded the MRL, denoting to a rate of greater than dimethoate's MRL

373 of $36 \%$. For diazinon, the occurrence rates in the water morning glory samples were 53\% (39/74)

374 and 79\% (48/61) for the samples from local markets and supermarkets, respectively (Figure 3).

375 Only one sample of the water morning glory purchased from the local markets had diazinon

376 exceeding the recommended MRL (10 ppb). None of the water morning glory samples from the

377 supermarkets had diazinon levels above the MRL value. Carbofuran and cypermethrin were

378 detected in the water morning glory samples from both the local markets and supermarkets with

379 moderate occurrence rates. Carbofuran was found in the morning glory samples with occurrence

380 rates of $32 \%(24 / 74)$ and $28 \%(17 / 61)$ for the local markets and supermarkets, respectively. All

381 of the water morning glory samples tested had carbofuran levels below its recommended MRL.

382 Cypermethrin was found in $11 \%(8 / 74)$ of the water morning glory samples bought from the

383 local market samples, while $26 \%(16 / 61)$ of the supermarket samples contained cypermethrin

384 (Figure 3). Five of the water morning glory samples (7\%) from the local markets had

385 cypermethrin that exceeded its MRL (700 ppb). Out of the supermarket samples, four samples

386 (7\%) had cypermethrin exceeding the recommended MRL. Chlorpyrifos was also detected in the

387 water morning glory samples from the local markets and supermarkets with low rates of

388 occurrence. It was found in $7 \%$ of the water morning glory samples bought from the local market

389 samples, while $21 \%$ of the supermarket samples contained chlorpyrifos (Figure 3 ). One sample

390 of the water morning glory from both the local markets and the supermarkets had chlorpyrifos

391 that exceeded the MRL (50 ppb). Other six pesticides including carbaryl, chlorothalonil, $\lambda$ -

392 cyhalothrin, malathion, methomyl and profenofos were detected in the water morning glory

393 samples, although their occurrence rates were very low (Figure 3). Of note, some of pesticides

394 mentioned were not detected in both the local market samples and the supermarket samples. For

395 example, carbaryl and chlorothalonil were detected only in the supermarket samples, but not

396 found in the water morning glory samples bought from the local markets.

397 The overall incidence of pesticide detection in the water morning glory samples purchased

398 from local markets and supermarkets. Small proportions of samples were found to contain no

399 pesticide residues; this represents a rate of free of pesticide-free residue of $1 \%$ and $3 \%$ in the

400 local and supermarkets, respectively. Extremely high percentages of pesticide detection, i.e.,

$40199 \%$ and $97 \%$ were observed in the morning glory samples bought from the local markets and

402 supermarkets, respectively. The incidence of pesticide residues detected exceeding the 
403 recommended MRL values in the morning glory samples from local markets was $42 \%$ whereas

404 the incidence rate of $49 \%$ was observed in the supermarket samples.

405 The profiles of pesticides detected in the three vegetables investigated are shown for

406 comparison (Table 1). Details of the pesticides detected in the three studied vegetables and their

407 concentrations can be accessed online from the Supplementary data. From 28 pesticides studied,

40813 were found in the fresh samples of these three popularly consumed vegetables. Nine

409 pesticides were found to be common pesticides detected in all the three vegetables studied. These

410 were carbaryl, carbofuran, chlorpyrifos, $\lambda$-cyhalothrin, cypermethrin, diazinon, dimethoate,

411 metalaxyl and profenofos. Methomyl was not detected in the Chinese kale and pakchoi samples.

412 Chlorothalonil, deltamethrin, metathion and methomyl were not found in the pakchoi samples,

413 while deltamethrin was also not detected in the morning glory samples.

414 Table 2 shows comparison of pesticide concentrations in the three vegetables studied found

415 in the samples bought from the local markets and the supermarkets. Both mean as well as median

416 data were evaluated and are presented in Table 2. All the pesticide concentrations detected in

417 these vegetables were found to be not normally distributed; therefore, the data was then

418 statistically evaluated by the non-parametric Mann-Whitney test. Subsequently, the median data

419 was used to compare the differences in concentrations of pesticides between the two groups, the

420 local market and the supermarket samples. For the Chinese kale, the median concentrations of

421 dimethoate and profenofos were similar $(P>0.1)$ between the samples from the local markets

422 and the supermarkets. However, the median concentrations of diazinon and metalaxyl in the

423 Chinese kale samples purchased from the supermarkets were significantly greater than those

424 detected in the samples purchased from the local markets $(P<0.001$, Table 2$)$. With regard to

425 results in pakchoi, the median concentrations of three pesticides, dimethoate, diazinon and

426 metalaxyl in the local market samples were not significantly different from those found in the

427 supermarket samples $(P>0.05)$. Though, the median concentrations of carbofuran in the pakchoi

428 samples bought from the supermarkets were significantly higher than those observed in the local

429 markets $(P<0.001$, Table 2$)$. For the morning glory samples, there were no significant

430 differences between the samples from the local markets and the supermarkets in median

431 concentrations of pesticides. The exception to this was for the median concentration of diazinon

432 in the supermarket samples was significantly higher than that seen in the local markets $(P<0.01$,

433 Table 2). 
The GC-MS/MS methods established in our laboratory (Wanwimolruk et al., 2015b) involving QuEChERS sample preparation and GC-MS/MS analysis, were validated. The methods were proven to be suitable and appropriate for determination of pesticide residues in the three leaf vegetables namely Chinese kale, pakchoi and morning glory. This was verified by results of assay validation which have illustrated good recovery, sensitivity, selectivity, linear calibration curves, good reproducibility and accuracy. The utilizations of GC combined with triple quadrupole MS technique not only aided the detection and quantitation of pesticides but it also offered excellent sensitivity for pesticide detection.

The present study examined potential contamination of 28 pesticides in three leaf vegetables namely Chinese kale, pakchoi and morning glory sold in Thailand. Twelve pesticides were detected in fresh Chinese kale samples bought from the local markets and the supermarkets. These included carbamates (carbaryl, carbofuran), organochlorines (chlorothalonil), organophosphorus pesticides (chlorpyrifos, diazinon, dimethoate, malathion, profenofos), pyrethroids ( $\lambda$-cyhalothrin, cypermethrin, deltamethrin), and metalaxyl. Findings of so many pesticides detected in this vegetable indicate that pesticides are widely and extensively used in the agronomy of Chinese kale in Thailand. This observation is in agreement with our recent finding in which many pesticide residues were detected in Chinese kale sold in Thailand (Wanwimolruk et al., 2015b). Also, this is consistent with those previously observed pesticide contamination in vegetables in Thailand and other Asian countries (Chang et al., 2005; Sapbamrer \& Hongsibsong, 2014; Swarnam \& Velmurugan, 2013). A study carried out in a northern part of Thailand (Sapbamrer \& Hongsibsong, 2014) reported that vegetables bought from markets contained organophosphorus pesticides greater than the recommended MRLs.

459 These vegetables included garlic, Chinese cabbage, spring onion, Vietnamese coriander and 460 Chinese kale. These findings with respect to Chinese kale agree with our observation in which 461 the levels of three organophosphorus pesticides (chlorpyrifos, dimethoate and profenofos) were 462 greater than their corresponding MRL values. In the present study, there were five pesticides, 463 namely carbofuran, chlorpyrifos, cypermethrin, dimethoate and profenofos, which were detected 464 in some samples at levels exceeded the MRLs (Figure 1). This implies that the Thai farmers used 
465 these pesticides in excessive doses or did not follow the GAP in which an appropriate pre-

466 harvest interval, i.e., the time period between the last pesticide application and a safe harvest of

467 the treated crop, was not considered. Although metalaxyl and diazinon were among the most

468 often detected in the Chinese kale samples, the pesticide residue concentrations found were not

469 exceed their corresponding MRL values. Moreover, finding with large proportion of the Chinese

470 kale samples (90\%) contained multiple pesticide residues (Figure 1), clearly indicating that the

471 Thai farmers are likely to use more than one pesticide during the cultivation of Chinese kale.

472 Observation on similar types of pesticides detected in these commonly three individual

473 vegetables (Table 1) indicates that Thai farmers cultivated these vegetables in the same areas of

474 their farm, as it is easy to water and protect these vegetables from pests by using the same

475 mixture of pesticides. Another reason could be that Thai farmers producing these vegetables are

476 neighbors and grouped their farms together. Among the pesticides used in cultivation of these

477 three leafy vegetables, metalaxyl, dimethoate and diazinon were the most often used pesticides.

478 Moreover, the similarity in the profiles of pesticides detected in these three commonly consumed

479 vegetables studied, suggests that it is an advantage to reduce the cost for the pesticide monitoring

480 by selecting to monitor the pesticide residues in only one of these vegetables. The results from

481 any of these three vegetables will be eventually applied to those of the other two counterparts.

482 Both extent and incidence of pesticide contamination observed in each vegetable were similar

483 between the samples from both sources the local markets and the supermarkets. For instance,

484 most of the twelve pesticides found in the Chinese kale were detected in both samples from the

485 local markets and the supermarkets. The exception was three pesticides detected in the Chinese

486 kale samples were not found in the samples from both sources, i.e., the local markets and the

487 supermarkets. Chlorothalonil and deltamethrin were not detected in the local market samples,

488 while a few samples from the supermarkets were contaminated with residues of these pesticides.

489 Malathion was found in only one Chinese kale sample from the local markets but not in the

490 samples from the supermarkets. Similar findings were seen in the other two vegetables (pakchoi

491 and morning glory) regarding minor differences in pesticides detected in the samples from the

492 local markets and the supermarkets. These minor differences in the profiles of pesticides found

493 in the three commonly consumed vegetable samples from the local markets and the supermarkets

494 may be related to the sources (or farms) where the vegetables were cultivated, difference of

495 usage of each type of pesticides, and ignorance of GAP awareness. Traceability of the produces 
496 was hard to attain and ultimately this was not the primary goal of the current study. If available,

497 the traceability would have been very useful for interpretation of the data obtained from this

498 study. The merchants were in fact asked where they bought the vegetables from and habitually

499 many of them did not have an answer. For those who provided an answer, it appeared that most

500 of the vegetable samples tested were bought from four different whole sale markets in Bangkok

501 and Nakhon Pathom province situated near Bangkok. Future studies are required to trace the

502 farms where the vegetables are cultivated and to identify the factors or farmers' behaviors that

503 attribute to the differences in rates of the pesticide detection and the MLR exceedance. Vitally,

504 proper education such as GAP regarding the appropriate use of pesticides must be provided to

505 these farmers.

506 The present study revealed overall incidence of pesticide detection in the three vegetables

507 studied was in a range from $97-100 \%$. For the Chinese kale, this high incidence of pesticide

508 detection is consistent with our previous study published recently (Wanwimolruk et al., 2015b).

509 In that study, an incidence of pesticide detection of $85 \%$ was reported in the Chinese kale

510 collected in Nakhon Pathom province of Thailand. Characteristics and sources of the samples

511 were similar to those tested in the present study. It is obvious that these figures of the incidence

512 of pesticide detection observed in the three commonly consumed vegetables are noticeably

513 higher than the tolerable detection rate in western or developed countries, such as USA and

514 European Commission (EC) countries like France, U.K., Norway and Germany. For example,

515 the US FDA carried out a monitoring program of vegetables with thousands of domestic samples

516 and imported samples (Granby et al., 2008). Pesticide residues were found in $30 \%$ of the

517 domestic vegetables and $21 \%$ of the imported vegetables. In Taiwan, pesticide residues were

518 detected in 14\% of 9,955 vegetable samples tested (Chang et al., 2005). A survey study

519 conducted in India found residues of many organophosphorus pesticides (e.g., chlorpyrifos,

520 dimethoate, monocrotophos and profenofos) in $54 \%$ of the vegetable samples (Swarnam \&

521 Velmurugan, 2013). The latest study from Thailand (Sapbamrer \& Hongsibsong, 2014)

522 conveyed an overall pesticide detection rate of $25 \%(\mathrm{~N}=106)$ in various vegetables bought from

523 the markets. This rate is nevertheless much lower than the rates of pesticide detection in the

524 Chinese kale, pakchoi and morning glory observed in this study. The difference may be

525 accounted for by differences in seasons of vegetable cultivation, vegetable types, types of

526 pesticides used and analytical methods employed. 
Remarkably, the occurrence of pesticide detection exceeding the MRL in the three vegetables studied ranged from 35 to $71 \%$; it was high in both samples from the local markets and the supermarkets. These were noticeably high, as compared with the incidence testified in developed countries. For instance, the US FDA declared that violations (with pesticide concentration $>$ MRL) were found in 2\% of the domestic and $7 \%$ of the imported vegetable samples (Granby et al., 2008). The European Union (EU) Monitoring Program for pesticides declared that 5\% of vegetable samples examined had the pesticide residue concentrations that exceeded the MRL (Granby et al., 2008). In Asia, a study carried out in Taiwan reported that of 9,955 samples tested, 1.2\% were violating the MRL (Chang et al., 2005). Therefore, the incidence of pesticide detection of $>$ MRL in our three vegetables, at rates of 32 to $49 \%$ are unusually high when compared with acceptable rates reported in developed countries. Nevertheless, these incidence rates are somehow similar to that found in Pakistan, an Asian country, in which 206 different vegetables were analyzed for 24 pesticides, and $46 \%$ had levels greater than the MRL (Parveen et al., 2005). Also, a study from India (Swarnam \& Velmurugan, 2013) reported that $15 \%$ of vegetable samples tested contained pesticide residues that exceeded the MLR values. In addition, the incidence of pesticide detection of $>M R L$ was stated to be $24 \%$ in several market vegetables examined in northern districts of Thailand (Sapbamrer \& Hongsibsong, 2014). This rate of pesticide detection is quite comparable to the rates reported in the present study. Recently, the Food and Drug Administration (FDA), Ministry of Public Health of Thailand issued a report on the pesticide monitoring program for vegetables and fruits in which more than 60,000 samples were screened each year (Srithongkum, 2014). The report revealed that violations found in vegetables and fruits marketed in Thailand were in a range of 5\% in the year 2011 to $4 \%$ in the year 2013. These rates reported by the Thailand FDA were approximately 7-14 times lower than the incidence of pesticide detection exceeding the MRL (35-71\%) found in this study. The conflicting findings are likely to be accounted for by the difference in methods utilized in the two survey studies. The survey by the FDA of Thailand was done by using a cholinesterase inhibition assay kit called GT-Test kit. This assay kit is competent of detecting two groups of pesticides, 554 i.e., carbamates (carbofuran and methomyl) and organophosphates (dicrotophos and EPN).

555 Nevertheless, unlike our current GC-MS/MS method, the GT-Test kit cannot offer a quantitative 556 analysis like most analytical methods, such as UV spectrophotometric assays, LC-MS/MS and 
558 has less sensitivity and does not provide a quantitative determination of pesticide concentration.

559 Thus, these restrictions of the kit assay can underestimate the incidence of MRL violations.

560 Unusually high rate of exceedance of the MRL found in the three vegetables investigated

561 may be due to the fact that we used the recommended MRLs adopted from those employed in

562 developed countries, i.e. Codex Alimentarius Commission (2015), and European Commission

563 (2015). Some of MRLs for pesticides used may be too low and made the incidence unnecessarily

564 high. For examples, MRL values for carbofuran were $20 \mathrm{ppb}(0.02 \mathrm{ppm})$ for Chinese kale and

565 pakchoi; and $10 \mathrm{ppb}$ (as a default value) for the morning glory. The MRLs for profenofos were

$56610 \mathrm{ppb}(0.01 \mathrm{ppm})$ as a default value, for Chinese kale and morning glory; and $50 \mathrm{ppb}$ for the

567 pakchoi. Using these low recommended MRLs yielded the remarkably high rate of MRL

568 exceedance observed in the present study. In addition, it should be noted that our findings were

569 limited to these three vegetables sold in a small number of central provinces of Thailand and did

570 not reflect the figure for the whole country. This is because the sample sizes were considerably

571 rather small. Larger sample sizes collected from many provinces of different regions in Thailand

572 would be required to verify the incidence of pesticide contamination. Importantly, health risk

573 assessment due to consuming these pesticide contaminated vegetables, has not yet been

574 evaluated. A larger sample size would be necessary for that as well.

575 There were substantial variations in the levels of pesticides found in the three vegetables

576 studied. For instance, profenofos levels found in the Chinese kale samples varied widely among

577 the samples from both sources ranging from 0.1 to 2,095 ppb; and levels of carbaryl found in

578 these samples ranged from 0.1 to $606 \mathrm{ppb}$. In addition, the large S.D. values (relative to their

579 corresponding means) were found for each pesticides detected in the Chinese kale and also in the

580 other two vegetables. This reflects the huge variation in concentrations of each pesticide detected

581 in the three commonly consumed vegetables. The large variation in the level of pesticides

582 detected in the vegetables may be due to many factors influencing the pesticide residues that

583 remained on the vegetables at the time of harvest. These factors include the dosage of pesticides

584 applied, dosing frequency and the pre-harvest interval for crops (Banerjee et al., 2006; Zhang et

585 al., 2012). Appropriate education on pesticide use and the pre-harvest interval for crops is

586 necessary. This education will assist to lessen the amount of pesticide residues remaining in

587 vegetables and fruits. 
588

589

590

591

592

593

594

595

596

597

598

599

600

601

602

603

604

605

606

607

608

609

610

611

612

613

614

615

616

617

618

Critically, the remarkably high rate of exceedance of the MRL (ranged from 35 to $71 \%$ ) found in the three commonly consumed vegetables reported in the present study indicates that these vegetables either purchased from both the local markets and the supermarkets are highly contaminated with pesticide residues. Regarding Thai people's expectations of supermarket produce, the findings in this study raises question to the quality of the vegetables marketed in supermarkets in Thailand. Quality of vegetables sold in the supermarkets in Thailand is, in general, thought to be good with regard to levels of pesticide contamination. Thai people's perception of supermarket vegetables and fruits is high with respect to quality and freshness. Most Thai consumers believe the labels placed on the produce sold in the supermarkets in which they are claimed to be pesticide-free or organic produce. However, these labels and claims are made without scientific evidence and testing to support them. The quality, in terms of pesticide contamination of vegetables sold in the local markets in Thailand is not guaranteed, as the routine national monitoring programs of pesticide residues is not fully implemented (Wanwimolruk et al., 2015b). The existing evidence points to considerable food safety problems, since pesticide residues were noticeably detected in vegetables sampled from the local markets in Thailand (Sapbamrer \& Hongsibsong, 2014; Wanwimolruk et al., 2015b). Such quality of these three commonly consumed vegetables marketed in Thailand appears to be similar regardless where the vegetables are purchased from, i.e. from local open-air markets or supermarkets. The present study has also demonstrated that there was similarity in the profiles of pesticides detected in the three commonly consumed vegetables from these two sources. In addition, the current study did not aim to compare organically grown and conventional grown vegetables but rather to compare the quality of the three commonly consumed vegetables bought from local markets and from supermarkets, in term of pesticide contamination. As previously mentioned, the vegetables sold from supermarkets of Thailand were categorized into four groups, i.e., conventional, organic, pesticide-free and safe vegetables. However, most of vegetables sold in the supermarkets have claimed to be either organic and pesticide-free produce. Such statements issued by the supermarkets are not always reliable. Our study did not test all organically grown vegetables in Thailand, so the findings are limited to the three vegetables studied. Future studies are warranted to verify if the produce sold in the supermarkets claiming to be organic and pesticide-free are of better quality than the conventionally grown produce (in terms of pesticide contamination). 
619 The prices of vegetables and fruits sold in supermarkets in Thailand are substantially higher 620 (2-6 times) than the produce sold in the local open-air markets. For example, the average price of 621 Chinese kale from supermarkets was $112 \pm 44$ Bahts $/ \mathrm{kg}$, (approximately US\$3.4/kg) which was 622 more expensive than those from local markets (38 \pm 8 Bahts $/ \mathrm{kg}$, US\$1.1/kg). In spite of this, for 623 some pesticides such as diazinon and metalaxyl, the levels of these pesticides in the Chinese kale 624 samples from the supermarkets were significantly higher than those seen in the samples from the 625 local markets (Table 1). A similar observation was also found in the other two vegetables 626 investigated, pakchoi and morning glory. This implies that the level of pesticide contamination 627 of these three commonly consumed vegetables cannot be warranted by the price of the produce.

628 However, it may be correct that vegetables and fruits purchased from the supermarkets are 629 fresher than those from local open-air markets.

630 Our findings also emphasize the fact that these three commonly consumed vegetables, 631 namely Chinese kale, pakchoi and morning glory, sold in the supermarkets in Thailand are not 632 pesticide-free or organically grown as the merchants stated on the produce labels. This problem 633 is challenging the Thai government authorities such as Thai FDA and the Department of 634 Agriculture. The financial sponsor of this study, the Agricultural Research Development Agency 635 (Public Organization) of Thailand requested us, as researchers to disseminate our findings 636 through the Thai government authorities in order to facilitate the implementation of regulations 637 and laws on pesticide residues and food safety. The Thai government authorities have been 638 informed about the findings raised from this study. Further action has been planned: to rectify 639 situation with the supermarket stakeholders, continue pesticide monitoring program, reinforce 640 the laws, and properly instate the GAP system to the farmers. These are very important not only 641 to reduce the health risks of consumers associated with pesticide residues in vegetables but also 642 to protect consumers' rights. The consumers who buy produce labeled organic pay more so 643 should get a higher quality, pesticide-free produce.

\section{CONCLUSIONS}

646

647 There is considerable contamination of pesticides in these three commonly consumed 648 vegetables in Thailand, i.e., Chinese kale, pakchoi and morning glory. Nine to twelve pesticides 649 were detected in these vegetables at detection rates of $97-100 \%$. The rate of pesticide residues 
650 exceeding the MRL in these vegetables studied were remarkably high as compared to those 651 reported in developed countries. The incidence of pesticide contamination was found to be 652 similar between the vegetables bought from local markets and supermarkets. These findings 653 questioned the quality of vegetables claimed to be pesticide-free sold in the supermarkets and 654 urged the attention of the Thai government authorities to solve this important problem. This 655 conclusion excludes Thai export quality vegetables and fruits that are routinely monitored for 656 pesticide contamination before exporting. It is our recommendation for the Thai government 657 authorities to conduct a proper pesticide monitoring program for these three commonly 658 consumed local vegetables to protect the health of domestic consumers. The findings arisen from 659 this study would be also useful for the Thai government to ascertain the MRL of pesticides in 660 these three commonly consumed vegetables, and to incorporate other pest management strategies 661 toward the safe and appropriate use of pesticides.

662

\section{ACKNOWLEDGEMENTS}

We are thankful to Dr. Nipa Rojroongwasinkul, Institute of Nutrition, Mahidol University for her guidance in the statistical analysis, and Ms. Onnicha Kanchanamayoon for her help in GCMS analysis.

\section{REFERENCES}

Anastassiades M, Lehotay SJ, Stajnbaher D, and Schenck FJ. 2003. Fast and easy multiresidue method employing acetonitrile extraction/partitioning and "dispersive solidphase extraction" for the determination of pesticide residues in produce. Journal of AOAC International 86:412-431.

Banerjee K, Upadhyay AK, Adsule PG, Patil SH, Oulkar DP, and Jadhav DR. 2006. Rate of degradation of lambda-cyhalothrin and methomyl in grapes (Vitis vinifera L.). Food Additives and Contaminants 23:994-999. DOI:10.1080/02652030600838613

Cervera MI, Portoles T, Lopez FJ, Beltran J, and Hernandez F. 2014. Screening and quantification of pesticide residues in fruits and vegetables making use of gas chromatography-quadrupole time-of-flight mass spectrometry with atmospheric pressure chemical ionization. Analytical and Bioanalytical Chemistry 406:6843-6855. DOI:10.1007/s00216-014-7853-1

Chan PK. 1990. 2-5. Practical Considerations for the Development and Risk Assessment of Pesticides. The Journal of Toxicological Sciences 15:176-182. DOI:10.2131/jts.15.SupplementIV_176 
686

687

688

689

690

691

692

693

694

695

696

697

698

699

700

701

702

703

704

705

706

707

708

709

710

711

712

713

714

715

716

717

718

719

720

721

722

723

724

725

726

727

728

729

730

Chang J, Chen T, and Fang T. 2005. Pesticide residue monitoring in marketed fresh vegetables and fruits in Central Taiwan (1999-2004) and an introduction to the HACCP system. Journal of Food and Drug Analysis 13:368-376.

Chen C, Qian Y, Chen Q, Tao C, Li C, and Li Y. 2011. Evaluation of pesticide residues in fruits and vegetables from Xiamen, China. Food Control 22:1114-1120. DOI:http://dx.doi.org/10.1016/j.foodcont.2011.01.007

Chen MF, Chen JF, Syu JJ, Pei C, and Chien HP. 2014. Insecticide residues in head lettuce, cabbage, Chinese cabbage, and broccoli grown in fields. Journal of Agricultural and Food Chemistry 62:3644-3648. DOI:10.1021/jf405555w

Claeys WL, De Voghel S, Schmit JF, Vromman V, and Pussemier L. 2008. Exposure assessment of the Belgian population to pesticide residues through fruit and vegetable consumption. Food Additives and Contaminants Part A, Chemistry, Analysis, Control, Exposure and Risk Assessment 25:851-863. DOI:10.1080/02652030701854741

Codex Alimentarius Commission. 2015. Pesticide Residues in Food and Feed. Available at http://www.codex-alimentarius.net/pestres/data/pesticides/index.html (accessed 15 March 2015).

Dong F, Chen X, Liu X, Xu J, Li Y, Shan W, and Zheng Y. 2012. Simultaneous determination of five pyrazole fungicides in cereals, vegetables and fruits using liquid chromatography/tandem mass spectrometry. Journal of Chromatography A 1262:98-106. DOI:http://dx.doi.org/10.1016/j.chroma.2012.08.100

Drouillet-Pinard P, Boisset M, Periquet A, Lecerf JM, Casse F, Catteau M, and Barnat S. 2011. Realistic approach of pesticide residues and French consumer exposure within fruit and vegetable intake. Journal of Environmental Science and Health Part B, Pesticides, Food Contaminants, and Agricultural Wastes 46:84-91. DOI:10.1080/03601234.2011.534413

Duff M., Voglino M. 2012. Rapid and robust multi-residue pesticides analysis using the Bruker 320-MS GC triple quadrupole mass spectrometer. 2012, www.bruker.com/chemicalanalysis, (accessed 20 November 2014)

European Commission. 2015. Pesticide EU-MRLs. Available at http://ec.europa.eu/sanco pesticides/pub-lic/?event=substance.selection $\quad$ (accessed 7 March 2015).

Granby K, Petersen A, Hermann S, and Poulsen M. 2008. Levels of pesticides in food and food safety aspects. In: Tadeo J, ed. Analysis of Pesticides in Food and Environmental Samples. Boca Raton, FL, USA: CRC Press, 287-318.

Harnpicharnchai K, Chaiear N, and Charerntanyarak L. 2013. Residues of organophosphate pesticides used in vegetable cultivation in ambient air, surface water and soil in Bueng Niam Subdistrict, Khon Kaen, Thailand. The Southeast Asian Journal of Tropical Medicine and Public Health 44:1088-1097.

Huan Z, Xu Z, Jiang W, Chen Z, and Luo J. 2015. Effect of Chinese traditional cooking on eight pesticides residue during cowpea processing. Food Chemistry 170:118-122. DOI:10.1016/j.foodchem.2014.08.052

Koesukwiwat U, Lehotay SJ, and Leepipatpiboon N. 2011. Fast, low-pressure gas chromatography triple quadrupole tandem mass spectrometry for analysis of 150 pesticide residues in fruits and vegetables. Journal of Chromatography A 1218:70397050. DOI:10.1016/j.chroma.2011.07.094 
731

732

733

734

735

736

737

738

739

740

741

742

743

744

745

746

747

748

749

750

751

752

753

754

755

756

757

758

759

760

761

762

763

764

765

766

767

768

769

770

771

772

773

774

775

776

Lehotay SJ. 2007. Determination of pesticide residues in foods by acetonitrile extraction and partitioning with magnesium sulfate: collaborative study. Journal of AOAC International 90:485-520.

Lehotay SJ, Son KA, Kwon H, Koesukwiwat U, Fu W, Mastovska K, Hoh E, and Leepipatpiboon N. 2010. Comparison of QuEChERS sample preparation methods for the analysis of pesticide residues in fruits and vegetables. Journal of Chromatography A 1217:2548-2560. DOI:10.1016/j.chroma.2010.01.044

Li W, Tai L, Liu J, Gai Z, and Ding G. 2014. Monitoring of pesticide residues levels in fresh vegetable form Heibei Province, North China. Environmental Monitoring and Assessment 186:6341-6349. DOI:10.1007/s10661-014-3858-7

Nagendra Prasad K, Shivamurthy GR, and Aradhya SM. 2008. Ipomoea aquatica, An underutilized green leafy vegetable: a review. International Journal of Botany 4: 123129.

Osei-Fosu P, Donkor AK, Nyarko S, Nazzah NK, Asante IK, Kingsford-Adabo R, and Arkorful NA. 2014. Monitoring of pesticide residues of five notable vegetables at Agbogbloshie market in Accra, Ghana. Environmental Monitoring and Assessment 186:7157-7163. DOI:10.1007/s10661-014-3917-0

Parveen Z, Khuhro MI, and Rafiq N. 2005. Monitoring of pesticide residues in vegetables (2000--2003) in Karachi, Pakistan. Bulletin of Environmental Contamination and Toxicology 74:170-176.

Paya P, Anastassiades M, Mack D, Sigalova I, Tasdelen B, Oliva J, and Barba A. 2007. Analysis of pesticide residues using the Quick Easy Cheap Effective Rugged and Safe (QuEChERS) pesticide multiresidue method in combination with gas and liquid chromatography and tandem mass spectrometric detection. Analytical and Bioanalytical Chemistry 389:1697-1714. DOI:10.1007/s00216-007-1610-7

Sapbamrer R, and Hongsibsong S. 2014. Organophosphorus pesticide residues in vegetables from farms, markets, and a supermarket around Kwan Phayao Lake of Northern Thailand. Archives of Environmental Contamination and Toxicology 67:60-67. DOI:10.1007/s00244-014-0014-x

Sapbamrer R, and Nata S. 2014. Health symptoms related to pesticide exposure and agricultural tasks among rice farmers from Northern Thailand. Environmental Health and Preventive Medicine 19:12-20. DOI:10.1007/s12199-013-0349-3

Srithongkum W. 2014. Situation of food safety on consumption of vegetables and fruits in Thailand. The 1st National Conference on Food and Nutrition for Health Fruits and Vegetables for Nutrition Security. Bangkok, Thailand.

Swarnam TP, and Velmurugan A. 2013. Pesticide residues in vegetable samples from the Andaman Islands, India. Environmental Monitoring and Assessment 185:6119-6127. DOI:10.1007/s10661-012-3012-3

Thailand Ministry of Agriculture and Cooperation. 2013. Pesticide residues: maximum residue limits. Thai Agricultural Commodity and Food Standards. TAS 9002-2013, ICS 67.040. Available at http://www.acfs.go.th/standard/download/MAXIMUM_RESIDUE_LIMITS new.pdf (accessed 12 January 2015).

Wang S, Wang Z, Zhang Y, Wang J, and Guo R. 2013. Pesticide residues in market foods in Shaanxi Province of China in 2010. Food Chemistry 138:2016-2025. DOI:10.1016/j.foodchem.2012.11.116 
777
Wanwimolruk S, Kanchanamayoon O, Boonpangrak S, and Prachayasittikul V. $2015 a$. Food safety in Thailand 1: it is safe to eat watermelon and durian in Thailand. Environmental Health and Preventive Medicine 20:204-215. DOI:10.1007/s12199-0150452-8

Wanwimolruk S, Kanchanamayoon O, Phopin K, and Prachayasittikul V. 2015b. Food safety in Thailand 2: Pesticide residues found in Chinese kale (Brassica oleracea), a commonly consumed vegetable in Asian countries. Science of the Total Environment 447-455. DOI:10.1016/j.scitotenv.2015.04.114

Zhang F, Wang L, Zhou L, and Pan C. 2012. Dissipation and residues of monosultap in rice plant and environment. Bulletin of Environmental Contamination and Toxicology 88:362367. DOI:10.1007/s00128-011-0437-2 
791 Figure 1. Type of pesticides detected in the Chinese kale samples purchased from the local 792 markets $(n=69)$ and the supermarkets $(n=68)$. For each pesticide detected, the lower bars 793 are for samples from the local markets, and the upper bars are for samples from the 794 supermarkets.

795

Figure 2. Type of pesticides detected in the pakchoi samples bought from the local markets $(n=63)$ and the supermarkets $(n=62)$. For each pesticide detected, the lower bars are for samples from the local markets, and the upper bars are for samples from the supermarkets.

Figure 3. Type of pesticides detected in the morning glory samples bought from the local 80 markets $(n=74)$ and the supermarkets $(n=61)$. For each pesticide detected, the lower bars are for samples from the local markets, and the upper bars are for samples from the 803 supermarkets. 


\section{Figure 1}

Chinese kale

Figure 1. Type of pesticides detected in the Chinese kale samples purchased from the local markets $(n=69)$ and the supermarkets $(n=68)$. For each pesticide detected, the lower bars are for samples from the local markets, and the upper bars are for samples from the supermarkets. 
Chinese kale

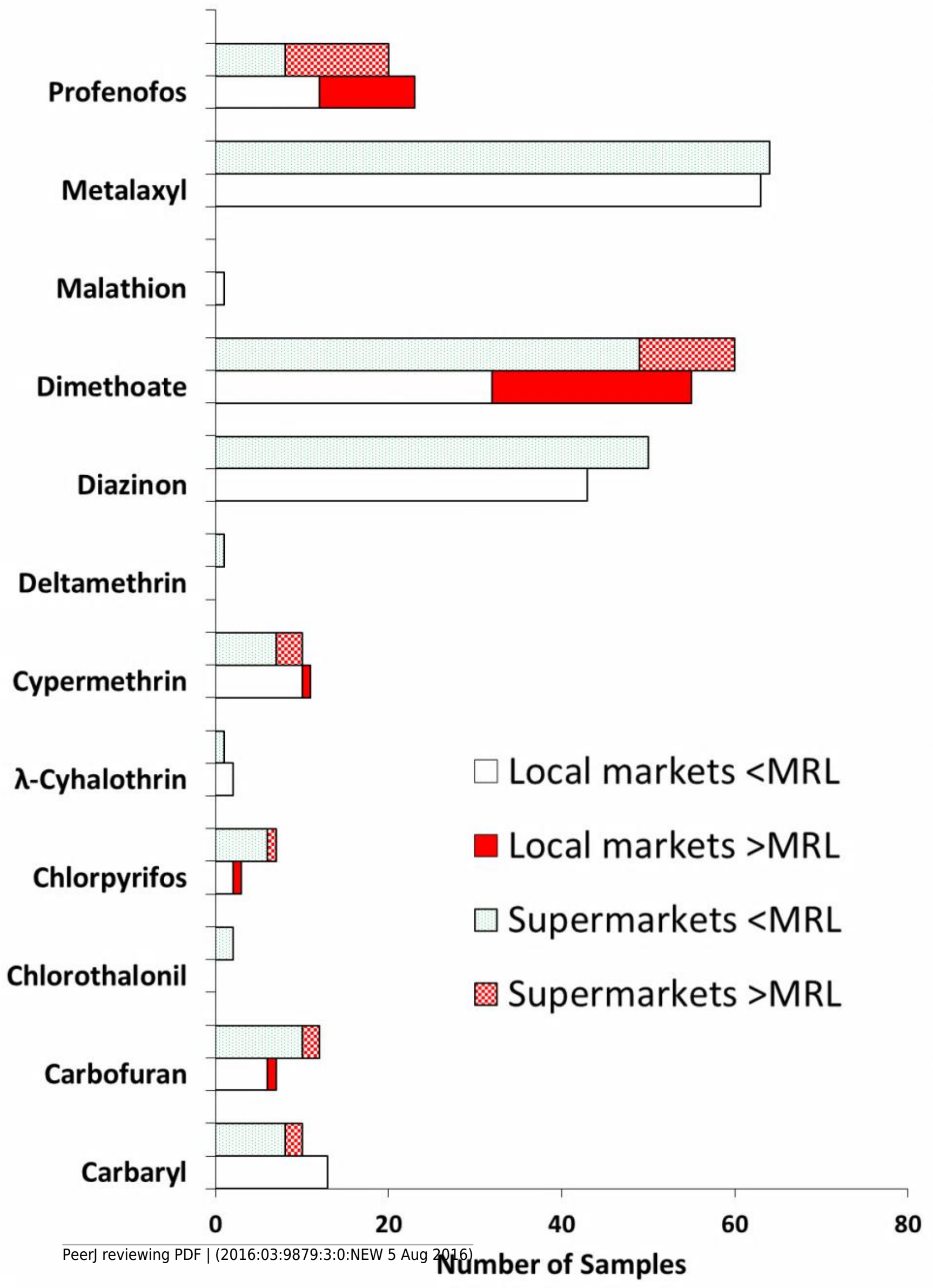


Figure 2

Pakchoi

Figure 2. Type of pesticides detected in the pakchoi samples bought from the local markets $(n=63)$ and the supermarkets $(n=62)$. For each pesticide detected, the lower bars are for samples from the local markets, and the upper bars are for samples from the supermarkets 


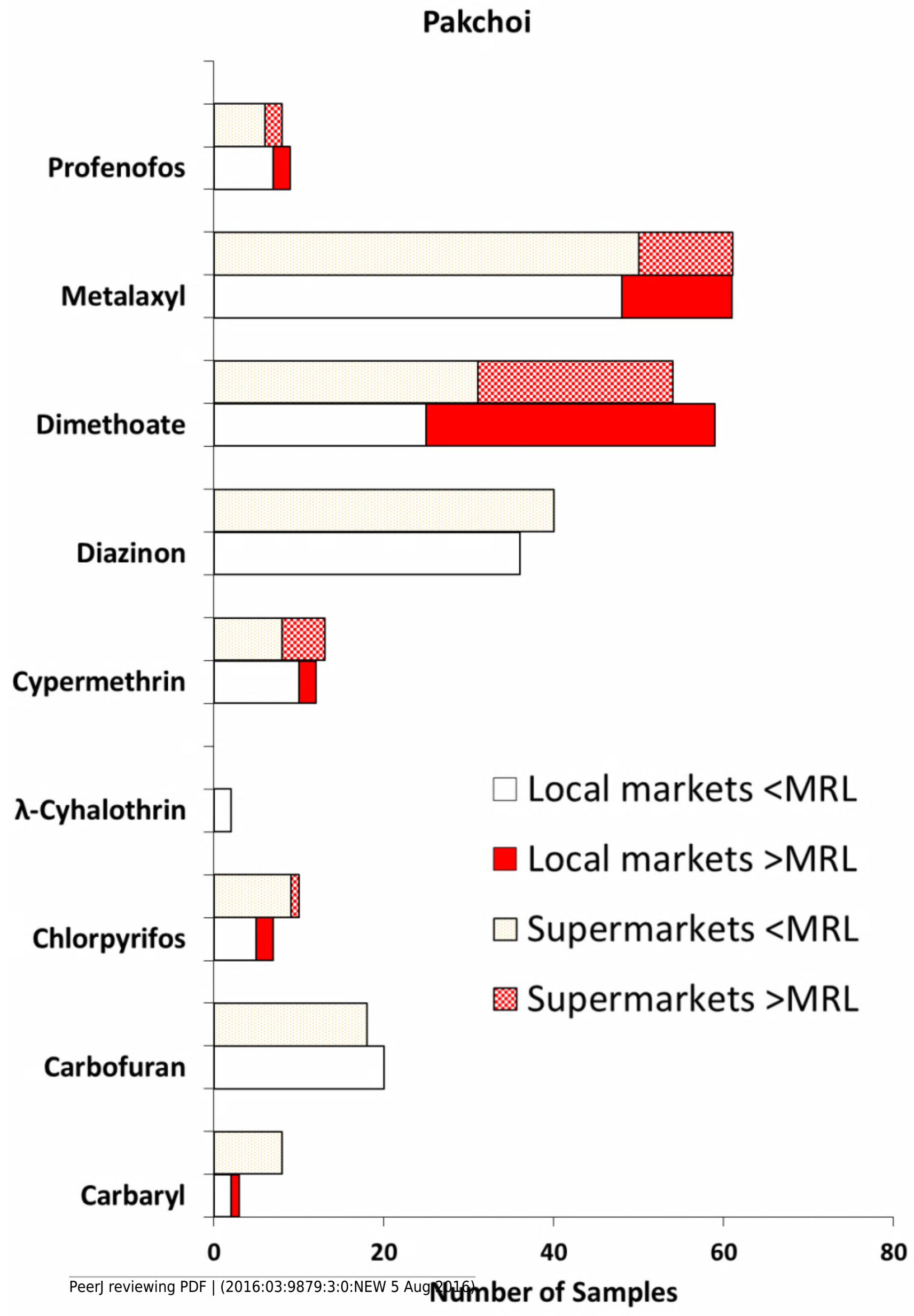


Figure 3

Morning glory

Figure 3. Type of pesticides detected in the morning glory samples bought from the local markets $(n=74)$ and the supermarkets $(n=61)$. For each pesticide detected, the lower bars are for samples from the local markets, and the upper bars are for samples from the supermarkets. 


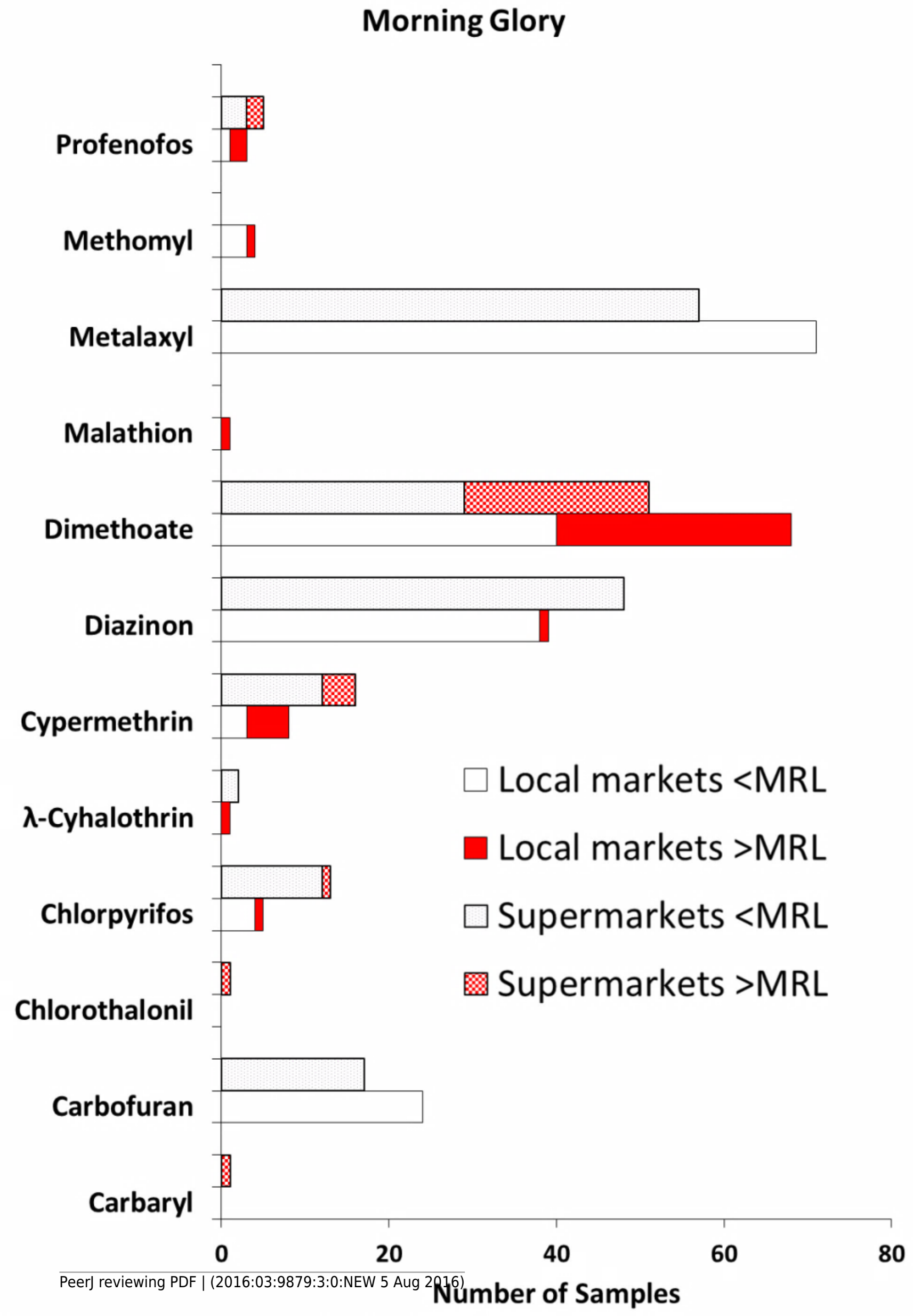




\section{Table $\mathbf{1}$ (on next page)}

Table \& MRL 
Table 1

2 Profile showing types of pesticide residues found in three commonly consumed vegetables studied, Chinese kale, pakchoi and morning glory

4

\begin{tabular}{|c|c|c|c|c|c|c|c|c|c|c|c|c|c|}
\hline Vegetable & 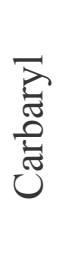 & 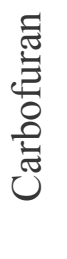 & 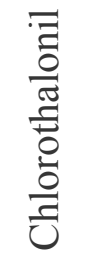 & $\frac{e_{0}^{\infty}}{\stackrel{0}{0}}$ & 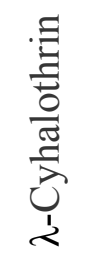 & 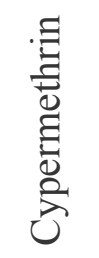 & 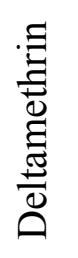 & 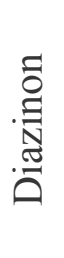 & 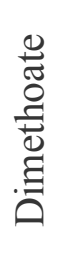 & 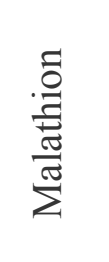 & 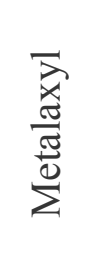 & 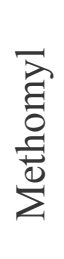 & $\begin{array}{l}0 \\
0 \\
0 \\
0 \\
0 \\
0 \\
0 \\
0\end{array}$ \\
\hline $\begin{array}{c}\text { Chinese } \\
\text { kale }\end{array}$ & $\checkmark$ & $\checkmark$ & $\checkmark$ & $\checkmark$ & $\checkmark$ & $\checkmark$ & $\checkmark$ & $\checkmark$ & $\checkmark$ & $\checkmark$ & $\checkmark$ & - & $\checkmark$ \\
\hline $\begin{array}{c}\text { MRL* } \\
(\mathrm{ppb})\end{array}$ & 50 & 20 & 4000 & 50 & 1000 & 1000 & 500 & 50 & 20 & 3000 & 2000 & - & 10 \\
\hline Pakchoi & $\checkmark$ & $\checkmark$ & - & $\checkmark$ & $\checkmark$ & $\checkmark$ & - & $\checkmark$ & $\checkmark$ & - & $\checkmark$ & - & $\checkmark$ \\
\hline $\begin{array}{c}\mathrm{MRL}^{*} \\
(\mathrm{ppb})\end{array}$ & 50 & 20 & - & 1000 & 1000 & 1000 & - & 50 & 20 & - & 50 & - & 50 \\
\hline $\begin{array}{l}\text { Morning } \\
\text { glory }\end{array}$ & $\checkmark$ & $\checkmark$ & $\checkmark$ & $\checkmark$ & $\checkmark$ & $\checkmark$ & - & $\checkmark$ & $\checkmark$ & $\checkmark$ & $\checkmark$ & $\checkmark$ & $\checkmark$ \\
\hline $\begin{array}{c}\mathrm{MRL}^{*} \\
(\mathrm{ppb})\end{array}$ & 10 & 10 & 10 & 50 & 20 & 700 & - & 10 & 20 & 20 & 2000 & 20 & 10 \\
\hline
\end{tabular}

$5 *$ MRL values for each pesticide in the vegetable studied were cited from recommended MRL

6 values established by Thailand Ministry of Agriculture and Cooperation (2013), Codex

7 Alimentarius Commission (2015), and European Commission (2015). 
Table 2 (on next page)

Table Median \& Statistical 


\section{Table 2}

2 Mean and median concentrations of six commonly detected pesticides in three vegetables 3 studied. $\mathrm{n}$ is number of samples in which the pesticide was detected.

\begin{tabular}{|c|c|c|c|c|c|c|}
\hline \multirow{3}{*}{ Pesticide } & \multicolumn{6}{|c|}{ Vegetables } \\
\hline & \multicolumn{2}{|c|}{ Chinese kale } & \multicolumn{2}{|c|}{ Pakchoi } & \multicolumn{2}{|c|}{ Morning Glory } \\
\hline & $\begin{array}{c}\text { Local } \\
\text { markets }\end{array}$ & Supermarkets & $\begin{array}{c}\text { Local } \\
\text { markets }\end{array}$ & Supermarkets & $\begin{array}{c}\text { Local } \\
\text { markets }\end{array}$ & Supermarkets \\
\hline Carbofuran & - & - & $\begin{array}{c}0.28(\mathrm{Med})^{\mathrm{a}} \\
(0.11,0.96)^{\mathrm{b}} \\
(\mathrm{n}=21)\end{array}$ & $\begin{array}{c}1.6(\mathrm{Med})^{*} \\
(1.1,3.5) \\
P=0.0002 \\
(\mathrm{n}=17)\end{array}$ & $\begin{array}{c}8.2 \text { (Med) } \\
(2.4,83.2) \\
(\mathrm{n}=71)\end{array}$ & $\begin{array}{c}7.7 \text { (Med) } \\
(3.2,33.4) \\
P=0.442 \\
(\mathrm{n}=57)\end{array}$ \\
\hline Dimethoate & $\begin{array}{c}10.5 \text { (Med) } \\
(2.3,30.1) \\
(\mathrm{n}=57)\end{array}$ & $\begin{array}{c}6.4 \text { (Med) } \\
(1.9,15.4) \\
P=0.17 \\
(\mathrm{n}=50)\end{array}$ & $\begin{array}{c}27.2 \text { (Med) } \\
(9.8,46.2) \\
(\mathrm{n}=59)\end{array}$ & $\begin{array}{c}18.6(\mathrm{Med}) \\
(4.7,40.2) \\
P=0.167 \\
(\mathrm{n}=55)\end{array}$ & $\begin{array}{c}10.4(\mathrm{Med}) \\
(3.4,34.6) \\
(\mathrm{n}=68)\end{array}$ & $\begin{array}{c}12.1 \text { (Med) } \\
(4.0,28.8) \\
P=0.737 \\
(\mathrm{n}=51)\end{array}$ \\
\hline Diazinon & $\begin{array}{c}0.28 \text { (Med) } \\
(0.13,1.7) \\
(\mathrm{n}=42)\end{array}$ & $\begin{array}{c}2.0(\mathrm{Med})^{*} \\
(0.82,4.2) \\
P=0.0004 \\
(\mathrm{n}=41)\end{array}$ & $\begin{array}{c}1.4 \text { (Med) } \\
(0.67,2.6) \\
(\mathrm{n}=36)\end{array}$ & $\begin{array}{c}1.8 \text { (Med) } \\
(1.1,3.6) \\
P=0.07 \\
(\mathrm{n}=40)\end{array}$ & $\begin{array}{c}1.1 \text { (Med) } \\
(0.62,1.6) \\
(\mathrm{n}=39)\end{array}$ & $\begin{array}{c}1.7 \text { (Med)* } \\
(0.97,2.7) \\
P=0.009 \\
(\mathrm{n}=48)\end{array}$ \\
\hline Metalaxyl & $\begin{array}{c}0.93 \text { (Med) } \\
(0.32,3.5) \\
(\mathrm{n}=61)\end{array}$ & $\begin{array}{c}10.8 \text { (Med)* } \\
(2.1,23.9) \\
P=0.0001 \\
(\mathrm{n}=52)\end{array}$ & $\begin{array}{c}8.8 \text { (Med) } \\
(2.1,36.1) \\
(\mathrm{n}=61)\end{array}$ & $\begin{array}{c}6.4(\mathrm{Med}) \\
(2.5,31.4) \\
P=0.8 \\
(\mathrm{n}=61)\end{array}$ & $\begin{array}{c}29.4(\mathrm{Med}) \\
(12.2,71.3) \\
(\mathrm{n}=27)\end{array}$ & $\begin{array}{c}24.8(\mathrm{Med}) \\
(5.8,64.0) \\
P=0.562 \\
(\mathrm{n}=27)\end{array}$ \\
\hline Profenofos & $\begin{array}{c}9.3 \text { (Med) } \\
(0.26,71.2)\end{array}$ & $\begin{array}{l}23.9 \text { (Med) } \\
(1.3,36.3)\end{array}$ & - & - & - & - \\
\hline
\end{tabular}




\begin{tabular}{|l|l|l|l|l|l|l|}
\hline & $(\mathrm{n}=28)$ & $P=0.39$ & & & & \\
$(\mathrm{n}=18)$ & & & & \\
\hline
\end{tabular}

$4{ }^{\text {a }}$ Median value

5 b 25 and 75 percentiles of the median value.

6 * Statistically significant differences in pesticide concentrations were observed between the local

7 market and the supermarket groups $(P<0.05)$. 